
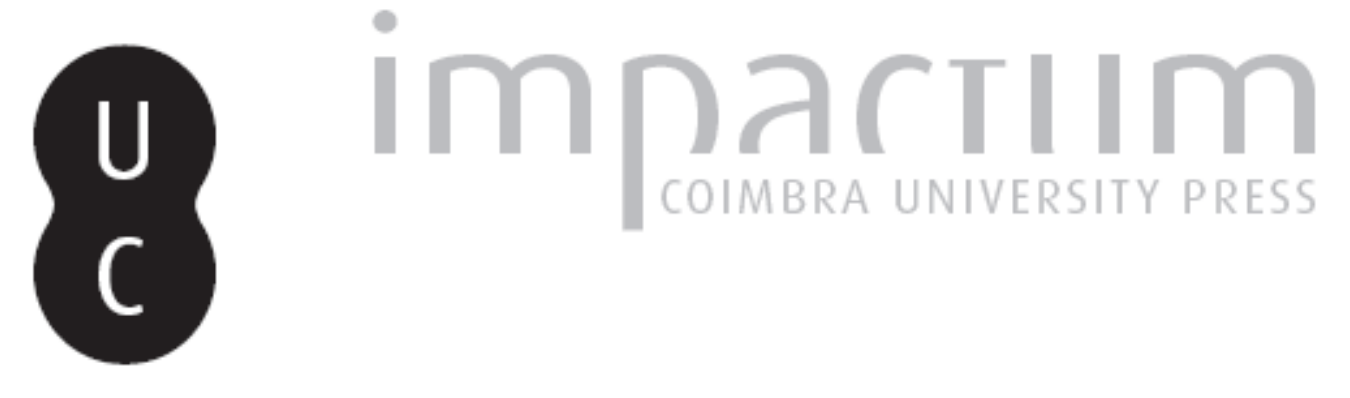

A paisagem cultural do Buçaco: a singularidade de um território turístico e de lazer Autor(es): $\quad$ Simões, Paulo Fernando Pereira Fabião

Publicado por: $\quad \begin{aligned} & \text { Faculdade de Letras da Universidade de Coimbra, Departamento de } \\ & \text { Geografia }\end{aligned}$

URL persistente:

URI:http://hdl.handle.net/10316.2/30215

DOI:

DOI:http://dx.doi.org/10.14195/0871-1623_32_14

Accessed : $\quad$ 26-Apr-2023 13:08:09

A navegação consulta e descarregamento dos títulos inseridos nas Bibliotecas Digitais UC Digitalis, UC Pombalina e UC Impactum, pressupõem a aceitação plena e sem reservas dos Termos e Condições de Uso destas Bibliotecas Digitais, disponíveis em https://digitalis.uc.pt/pt-pt/termos.

Conforme exposto nos referidos Termos e Condições de Uso, o descarregamento de títulos de acesso restrito requer uma licença válida de autorização devendo o utilizador aceder ao(s) documento(s) a partir de um endereço de IP da instituição detentora da supramencionada licença.

Ao utilizador é apenas permitido o descarregamento para uso pessoal, pelo que o emprego do(s) título(s) descarregado(s) para outro fim, designadamente comercial, carece de autorização do respetivo autor ou editor da obra.

Na medida em que todas as obras da UC Digitalis se encontram protegidas pelo Código do Direito de Autor e Direitos Conexos e demais legislação aplicável, toda a cópia, parcial ou total, deste documento, nos casos em que é legalmente admitida, deverá conter ou fazer-se acompanhar por este aviso.

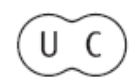




\title{
A paisagem cultural do Buçaco: a singularidade de um território turístico e de lazer
}

\author{
Paulo Fernando Pereira Fabião Simões
}

Doutorando em Turismo, Lazer e Cultura na Faculdade de Letras da Universidade de Coimbra. paulofsimoes@gmail.com

\section{Resumo:}

Ao longo dos tempos, o Buçaco serviu de cenário a acontecimentos do foro eclesiástico, militar, régio e romântico. O simbolismo representativo que o lugar carrega é uma realidade à qual não podemos ficar indiferentes. É um legado que nos foi deixado e merece ser protegido e dinamizado nos contextos de paisagem cultural, destino turístico e de lazer. A paisagem é dinâmica e por isso contém marcas deixadas por sucessivas transformações naturais e humanas. As paisagens são, também, património cultural, pois as pessoas identificam-se com determinadas porções de território, desenvolvem laços afetivos com ele e o território torna-se assim parte do(s) sujeito(s). Esta paisagem apresenta também uma forte centralidade ecológica, fato que, associado ao valor deste espaço geográfico enquanto memória lhe confere uma identidade singular com potencial para o desenvolvimento desta região.

Palavras-Chave: Paisagem Cultural. Turismo Cultural. Representações.

\section{Résumé:}

Paysage culturel du Buçaco: le caractère unique d'un territoire touristique et des loisirs.

Au fil du temps, le Buçaco a servi de toile de fond à des événements dans le forum ecclésiastique, militaire, royale et romantique. Le symbolisme représentant la place porte est une réalité à laquelle nous ne pouvons pas rester indifférents. C'est un héritage que nous ont laissé et mérite d'être protégée et rationalisés dans les contextes de paysage culturel, de loisirs et une destination touristique. Le paysage est dynamique et contient donc les marques laissées par des transformations successives de naturel et humain. Les paysages sont aussi le patrimoine culturel, parce que les gens s'identifient à certaines parties du territoire, et tout en développant des liens affectifs avec le territoire, le territoire devient une partie d'entre eux. Ce paysage a une forte centralité écologique, qui, associé à la valeur de la mémoire l'espace géographique, lui donne une identité unique pour le développement potentiel de cette région.

Mots-clés: Paysage Culturel. Représentation de Tourisme Culturel.

\section{Abstract:}

Cultural landscape of Buçaco: the uniqueness of a touristic territory and leisure

Over time, the Buçaco served as a backdrop to events in the ecclesiastical forum, military, royal and romantic. The symbolism representing the place carries is a reality to which we cannot remain indifferent. It is a legacy left to us and deserves to be protected and streamlined in the contexts of cultural landscape, leisure and tourist destination. The landscape is dynamic and therefore contains marks left by successive transformations of natural and human. The landscapes are also cultural heritage, because people identify with certain portions of territory, develop emotional ties with him and area becomes part of the subject. This landscape also has a strong ecological centrality, which, associated to the value of geographic space as memory, gives it a unique identity potential for the development of this region.

Keywords: Cultural Landscape. Cultural Tourism and Representations. 
Introdução

O estudo da paisagem é um exercício complexo e dinâmico que exige desmontar para perceber, relacionar, encontrar as marcas do tempo, as ironias da história, as formas de uso, as construções, onde diversos fatores naturais e culturais se influenciam mutuamente e se modificam ao longo do tempo.

Mas o conceito pode ser mais amplo, incluindo, além dos aspetos visíveis, os elementos imateriais como os cheiros, os sons e o tato, ganhando assim uma dimensão multissensorial. Segundo RIMBERT (1973), a noção de paisagem depende, antes de mais, da maneira de a apropriar, de apreender o espaço terrestre, ou seja, da imagem mental que se constrói da paisagem. Este autor acentua mesmo que somente as paisagens detentoras de um caráter subjetivo possuem um impacto afetivo capaz de orientar as decisões dos grupos e indivíduos.

Esta é uma reflexão acerca da forte centralidade ecológica que o Buçaco detém, fato que associado ao seu valor enquanto espaço geográfico e de memória the confere uma identidade singular com potencial turístico e de desenvolvimento local e regional.

\section{Reconhecimento da paisagem cultural}

Ao falar de paisagem cultural não se pode limitar apenas à esfera natural nem a humana, mas sim na forma como a sociedade e a natureza estão relacionadas entre si formando uma só "entidade" de um mesmo espaço geográfico.

As paisagens culturais são um "lugar" com uma forte matriz identitária sendo por isso consubstanciadas e construídas ao longo do tempo. A explicitação do "espírito do lugar" deve-se à sua dimensão imaterial e material e que se carateriza pelas manifestações culturais e comportamentos de uma comunidade.

O reconhecimento da "Paisagem Cultural" pode ser um elemento fundamental para a preservação e gestão do património natural e cultural, detendo uma relevância como dinamizadora de oportunidades pedagógicas e socioeconómicas e não só. A sua preservação irá depender de diversas variáveis, mas principalmente de políticas públicas que promovam modelos de desenvolvimento e regulação, compatíveis com a proteção das manifestações locais, dos saberes e fazeres, dos modos de produção, de ocupação e fraccionamento do solo e do incremento das suas potencialidades económicas, tais como o turismo e o lazer.
A paisagem é real e ao mesmo tempo representativa, sendo que ela faz parte da cultura e exprime as civilizações que nela habitam e deve ser encarada como o lugar do outro para que assim se possa observar as suas caraterísticas. A retórica paisagística é um meio de estabelecer, num determinado contexto cultural, a relação entre fisionomia e identidade territorial. 0 regresso à paisagem manifesta-se em vários domínios onde é necessário apreender a luz, as formas, os ambientes, para compreender os lugares e o sentido do espaço e do tempo.

A paisagem cultural tem sido descrita também como «nova paisagem» envolvendo outras dimensões valorativas, para além da «paisagem como quadro de vida» também a paisagem-património, a paisagem-valor de identidade, e a paisagem-recurso. Foram as revoluções da era industrial que paradoxalmente, vieram dar um novo impulso ao «paisagismo», nas artes, nas ciências, nas Humanidades, com efeitos nas representações dos lugares e dos territórios.

Paisagem multissensorial, vivências e espiritualidade

A paisagem aparece identificada, desde o século XVIII, pela sua expressão visível. A moda das viagens e a grande divulgação dada aos relatos do viajante no séc. XIX favoreceu, segundo LUGINBUHL (1992), a associação da paisagem às caraterísticas de um dado território, traduzidas na combinação local dos elementos naturais e humanos, devido ao modo particular como se aproveitam dos recursos.

A descoberta da paisagem através da pintura feita no Ocidente revela um novo interesse pela natureza, colocando uma visão diferente face ao ambiente natural e ao mundo em geral, contrariando a visão dada pelas escolas eclesiásticas. A observação começa assim a ser uma procura de emoções estéticas, semelhante ao que a pintura produz, abrindo caminho para novas descobertas para o seu funcionamento e a uma maior exploração e manipulação. A paisagem pode ser analisada por meio do aspeto visual, que varia de acordo com a percepção do observador, e pelo aspeto social, refletindo a realidade de um local em determinado período. Pode ser também analisada, como elemento fixo em constante transformação, como reflexo do espaço, ou seja, quando o espaço e a sociedade se transformam simultaneamente a paisagem também se transforma.

A Geografia Humana, encara a paisagem como um território, cada vez mais subjetivo e elaborado pela mente. As paisagens também exprimem os laços 
afetivos entre as pessoas e os lugares, cria-se um ícone paisagístico que corresponde ou traduz os valores dominantes da sociedade. Seja como fonte de sensações, seja como modo de ver um território, o fato é que se têm valorizado os aspetos subjetivos da relação das pessoas com o ambiente. Os lugares deixam de ser realidades fisionómicas e passam a ser construídos pela experiência e pela ligação afetiva do(s) individuo(s).

Salienta-se que o termo espaço é, em si mesmo, mais abstrato que o termo «lugar». Este termo serve para referirmos a um acontecimento (que teve lugar), a um mito (lugar dito), ou a uma história(s) (lugar histórico). Tratando-se de um termo eminentemente abstrato, e a sua utilização sistemática é, contudo, pouco diferenciada na linguagem corrente. Assim quando referimos um determinado espaço de lazer pode não ser sinónimo de um «lugar» na verdadeira acepção da palavra, sendo pois importante, estabelecer as respetivas diferenciações (AugÉ, 1994).

Em termos conceptuais, as pesquisas que se têm vindo a realizar sobre a paisagem têm feito ressaltar a importância de novas dimensões, incluindo o uso dos sentidos na apreensão das paisagens. Segundo GASPAR (2001) este renascimento dos estudos da paisagem em Geografia tem contemplado não só novos «olhares», como também a emergência de novas apreciações sensoriais da paisagem, com destaque para o olfato e para o ouvido. Entraram assim no vocabulário geográfico termos novos, como smellscape e soundscape. A relação do sujeito com o espaço é uma experiência sensorial ampla e complexa na qual intervêm os sentidos como o cheiro, o tato e a visão.

As paisagens olfativas, embora menos consciencializadas que as outras paisagens, deixam impressões fortes na memória dos lugares e dos momentos variando no espaço e no tempo e têm claras diferenciações de lugar para lugar. Ocupam uma presença importante nas memórias, que pode determinar decisões, com reflexos no ordenamento espacial das pessoas e das atividades (GASPAR, 2001). A abordagem sistemática das paisagens olfativas é feita pelo geógrafo canadiano J. DougLAs Porteous (1977; 1982; 1985), que terá mesmo «fundado» o conceito de smellscape afirmando que o homem, no seu processo de evolução social, tenha perdido muito da sua capacidade olfativa.

Os sons (Soundscape) são referências fortes nas leituras e memórias dos lugares, tanto pela presença como pela ausência. Só quando saímos da grande cidade e nos «embrenhamos» no campo ou na serra fora das fontes sonoras artificiais, é que nos apercebemos do como é poderoso este pano de fundo sonoro. Ao escutar o silêncio de uma planície ou praia deserta, é que compreendemos como o Soundscape de um espaço ou lugar pode ser libertador e reconfortante. Por isso o "som" é também um atrativo turístico, sobretudo em áreas de baixas densidades populacionais, sendo o Buçaco um lugar ideal para esta nova dimensão turística. Não podemos esquecer que os monges quando chegaram a este lugar no séc. XVII tinham, para além do isolamento (Isolatedscape), o Soundscape outro dos requisitos fundamentais para a construção do seu Deserto Carmelita.

Desde o século VI, a serra do Buçaco pertenceu ao Mosteiro dos Beneditinos da Vacariça, sendo também conhecido por Mosteiro Bubulense. Segundo PereIRA (2010) a ascensão da montanha com intuitos religiosos constitui um dos gestos rituais mais antigos da humanidade. Subir a montanha significa aproximar-nos do Céu, lugar por excelência onde residem os deuses. Mas mesmo no paganismo, a ascensão à montanha para comunicar com os deuses celestes, encontra-se na própria natureza terrestre e telúrica da montanha, nomeadamente nas entranhas da montanha ou nas suas grutas, caves e subterrâneos.

Por outro lado, a montanha participa igualmente no simbolismo «polar», isto é, no simbolismo do «centro», dada a sua estatura vertical. Indica o pólo celeste e coloca-o em contato canónico com a Terra. No âmbito do cristianismo, o simbolismo da montanha vai ser apropriado, especialmente a partir da Idade Média, assumindo a sua simultânea qualidade de «centro» - o centro religioso e o Buçaco teve um papel fundamental nesta (re)constituição simbólica espiritual.

A Mata Nacional do Buçaco considerada Monumento Nacional em 1943, vem trazer com o seu património botânico, paisagístico, arquitetónico, religioso, militar e histórico, um espaço impar no nosso país. Com a sua biodiversidade, o Buçaco constitui um santuário para algumas espécies raras, com grande abundância de água, traduzida em pequenos lagos naturais e artificiais, numerosas fontes e valores paisagísticos.

\section{Construção ideológica, memória e identidade}

A paisagem contém uma componente antropológica, uma memória deixada por sucessivas transformações humanas. As paisagens são património cultural, elemento imprescindível da identidade de um povo ou até de um modelo de coesão de um Estado pois as pessoas identificam-se com determinadas porções de território, desenvolvem laços afetivos com ele e o território torna-se assim parte do(s) sujeito(s). 
Surge-nos, também a ideia de que a paisagem é uma autobiografia coletiva que reflete gostos, valores e aspirações. As paisagens biográficas, percorrem os caminhos da vida de alguém que nos deixou memórias; são as paisagens que podemos visitar através de dois percursos, complementares. 0 da imaginação, auxiliada ou não por documentos (escritos, fotográficos, orais, edificados) ou revisitando com olhar retrospetivo a materialização, possível de uma vida (GASPAR, 2001).

A diversidade paisagística decorre tanto da sua longa espessura histórica como dos procedimentos que as comunidades diacronicamente encontraram para prover a sua subsistência. 0 papel dos lugares como referência de um determinado território é importante não só para compreender o aspeto mítico do lugar, como também, e sobretudo, para reconstruir identidades. Temos em Portugal um exemplo desta afirmação como é o caso do Buçaco, em particular durante o período conturbado do reinado de D. Carlos I. O edifício mandado construir em 1888 e que vem destruir quase por completo o convento Carmelita, influência da extinção das Ordens religiosas de 1834, reflete bem esta mudança de paradigma em que se transformou o lugar, fruto daquilo a que poderemos designar de modernidade. É na presença do passado no presente que o excede e reivindica que se pode ver a essência da modernidade.

A partir dos finais do século XIX, o Buçaco emerge num estatuto de lugar antropológico, materializado com itinerários, eixos ou caminhos traçado(s) pelo(s) homem e que nos conduzem a outros mundos. De lugar de pura austeridade monacal e prática espiritual, para um lugar identitário, relacional e histórico em que se usa a arquitetura para fazer uma representação cenográfica disso mesmo. Esta encenação pode ainda hoje, provocar comentários retrospetivos cujos espetadores de si próprios, turistas do íntimo cultural, não podem atribuir à nostalgia ou fantasias da memória as mudanças que testemunham com alguma tristeza, pois este já não é em parte, o lugar que foi concebido originalmente.

A simbólica política utiliza essas possibilidades para poder exprimir o poder da autoridade, que na unidade de uma figura soberana, unifica e simboliza as diversidades internas de uma coletividade social. É de assinalar que a identificação do poder com o lugar em que ele se exerce ou com o monumento que aloja, mesmo que temporariamente, os seus representantes, é uma regra constante no discurso político dos estados modernos. Por exemplo, a Casa Branca e ou o Kremlin, representam para aqueles que os nomeiam, lugares monumentais e estruturas de poder.
Apesar da mudança de paradigma a que o Buçaco se sujeitou, também reconhecemos que a dicotomia que imergiu daí veio contudo, trazer um valor intrínseco ao lugar. Para SAlgueIRo (2001), recordar os acontecimentos que marcaram um lugar é dar-lhe um significado, um espaço com dimensões de objetivar, que traduz as crenças e os valores da sociedade. É repositório da cultura e estilos de vida das formações sociais anteriores, base da ligação das pessoas ao território, que faz parte da memória e identidade dos indivíduos e das sociedades.

0 papel da paisagem na identidade local e regional já tinha sido destacado por RIBEIRo (1993), ao afirmar que a paisagem de hoje corresponde a um produto do passado e constitui por isso, um registo da memória coletiva. Neste contexto a paisagem torna-se um elemento poderoso de identificação cultural, como a língua e a religião e o mais espantoso é que, ainda como a língua e a religião, também a paisagem se atualiza (GASPAR, 1993).

Por outro lado, a paisagem enquanto representação e extensão territorial acaba de fato por não se diferenciar pois todo o espaço geográfico é um produto social, uma espacialização construída pela ação transformadora dos grupos sociais num processo contínuo que implica avaliação da realidade exterior.

A paisagem e o património cultural têm acima de tudo uma função social, cultural e humana, assumindo, também uma importância capital na identidade cultural dos povos. A memória cultural dos povos, isto é, a iconografia, está na base da cultura e nela está o homem. Ao preservarmos a paisagem cultural estamos a manifestar uma vontade de que no futuro, outros a possam desfrutar e, por outro lado, para que também, o equilíbrio das espécies e a vida na terra, dependa fundamentalmente desta atitude.

Estas representações têm valor patrimonial, evocativo do passado e de fixação da memória. A consolidação das identidades nacionais e a agregação em torno de ícones coletivos beneficiou também, da circulação de representações de paisagens, monumentos, ilustrações de acontecimentos históricos e personagens heróicas. O Buçaco é um desses ícones que teve um papel determinante num período histórico, que serviu (ou não) para consolidar a identidade nacional e reforçar a imagem da monarquia constitucional da época.

Se a paisagem cultural é, como já referimos um processo sempre em inovação, ela não é, contudo, ideologicamente neutra, concretiza-se em especial pela sua transformação como elemento inovador com narrativas únicas que marcaram a apropriação simbólica 
do espaço. A paisagem cultural do Buçaco é marcada pela sua dupla condição de espaço físico e de construção ideológica, tendo ficado como um ícone político e social, fruto do espírito da época dos descobrimentos, cenário de conflito de guerra, político, ideológico e imagem de referência de gloriosa memória do passado e de mística tradição.

A Guerra Peninsular desencadeada por Napoleão teve no Buçaco contornos dramáticos para o seu destino. A Terceira Invasão iniciou-se em Julho de 1810, sob o comando do Marechal Massena, onde a 27 de Setembro desse ano travou-se uma das batalhas mais decisivas da Terceira Invasão e para as forças Anglo-Portuguesas, ficando para a história como a Batalha do Buçaco.

Este acontecimento histórico foi de tal ordem importante que ao longo do tempo se tornou parte integrante do Buçaco, marcando-o como um lugar de referência na história militar portuguesa. Tal é a sua importância na memória coletiva, que ainda hoje se fazem recriações desta batalha junto ao seu monumento comemorativo, o Obelisco. Ele é também, um elemento transformador da paisagem, signo de um fato ocorrido no tempo, juntando-se ao vasto património deste lugar.

Fazendo um exercício cronológico o Buçaco abarca 200 anos de património edificado que vai do eclesiástico, passando pelo militar até ao romântico, todo ele contido numa mata com grande diversidade arbórea e vegetal, tornando-o num lugar de grande singularidade paisagística e cultural.

\section{Imagem(s) e narrativa(s) para o turismo}

O turismo apresenta um potencial de horizontes no que diz respeito à sua capacidade em fazer a comparação entre diferentes realidades. O turista "consome" visualmente o ambiente visitado, captando as imagens esteticamente construídas dentro das suas expetativas, onde o quotidiano, a natureza e o património são embelezados com padrões comportamentais, emoções e cores de forma a transformá-los singulares.

Neste contexto, a estrutura narrativa implícita vê o passado como nostálgico e idealizado. É com esta visão que o intangível e o imaterial se torna físico, adquire uma dimensão existencial, fruto de uma leitura renovada. Estas narrativas estão diretamente relacionadas com a formação-recriação das identidades, a educação e o usufruto do tempo de lazer.

As imagens (re) criadas e a construção de narrativas, são verdadeiros intermediários culturais com capacidade de retirar num quadro geográfico de referência, cenografias com detalhes e discursos fluidos e adaptáveis ao turista.

Segundo SAYYA (2001), todo o património é socialmente "manufaturado" e todas as tradições podem ser potencialmente consumidas. Podemos dizer que 0 turismo e mais especificamente o turismo cultural, encontra-se relacionado com o poder de sedução do lugar que exerce sobre o turista, com o propósito deste poder experimentar a "cultura" enquanto forma distinta da sua e de participar em novas experiências culturais, tanto no plano estético como no emocional.

As atividades que são desenvolvidas para ir ao encontro da sua curiosidade, podem assumir várias formas como participar em eventos locais no tempo e no espaço, como na própria observação direta de monumentos que se distinguem pelo seu passado. A importância que se dá a esta "experiência" do turista ou do visitante, é de tal ordem, que a própria Carta Internacional sobre o Turismo Cultural, adoptada pelo ICOMOS em 1999, expressa de forma inequívoca que "o planeamento da conservação e do Turismo nos Sítios com Património, deverá garantir que a experiência do Visitante mereça a pena, seja satisfatória e agradável"1.

Contudo, salienta-se que não se pretende defender a tese do caos, antes pelo contrário. Defende-se sim, que todo o turismo praticado, inclusive o do Buçaco, deve obedecer a uma estratégia sustentável assente num planeamento e uso dos recursos endógenos procurando sempre respeitar o lugar, resistindo à tentação do produto turístico desorganizado com vista a um resultado meramente economista.

Não se pretende, em momento algum, fazer uso substancial da imagem e da narratividade, numa atração (des)ordenada, uma mistura do tempo e do espaço em mundos imaginados para obter um turista fascinado num simulacro da imaginação que não é autêntica.

Ao longo dos tempos o turismo assumiu a forma perversa de alimentar as simulações culturais, os bens e espaços transformando-os em produtos representacionais, construídos e (ou) (re)adaptados para satisfazer as suas expetativas. Esta atitude torna o lugar vulnerável (des)personalizado retirando-o do seu contexto valorativo a curto prazo. 0 mito da cultura-destino paradísico e os produtos que promovem o seu consumo irão de fato prevalecer, se forem percepcionados como imaginações agradáveis sem autenticidade e pouco duradouras. Pensamos que aqui o aspeto educativo tem mais peso, sendo duradouro na formação e reconhecimento do nosso

${ }^{1}$ Veja-se a Carta Internacional sobre Turismo Cultural em http:// www.icomos.org/fr/ 
património e isso sim o turismo como veiculo indutor pode ter um papel significativo para a promoção desses valores.

A autenticidade não tem forçosamente de coincidir com a materialidade construída no lugar. Ela tem mais sentido no modo como é apresentada numa determinada interpretação, os valores que a comtemplam e com a estética que a espelham. Uma tradição, cultura, ou paisagem, não devem ser consideradas só pela forma como as percepcionamos. A experiência deve ser real. Ela é real, autêntica e singular, sempre que seja considerada por quem a protagonize.

Ainda que alguns se empenhem em vender a autenticidade ela cria-se individualmente sendo contextualizado nas próprias experiências do sujeito, representando uma alternativa de experiências que compensa as regras e a rotina do quotidiano. 0 turismo pode estabelecer uma forma de ver e sentir o mundo, se for orientado por uma sensibilidade estética e por predisposições patrimoniais, culturais e educativa.

\section{Considerações finais}

Este percurso pela bibliografia geográfica sobre a paisagem revela como a importância deste conceito variou no tempo e está ligada a diferentes correntes de pensamento. Demonstra que sempre existiu uma ambiguidade em torno do conceito de paisagem, que deriva da diferença entre aquilo que se vê (a realidade) e o modo como é visto. Esta dualidade leva-nos a distinguir a paisagem objetiva, da paisagem subjetiva, ou seja, a ideia que se tem dela.

Hoje sabemos que a paisagem é frágil, especialmente no período em que vivemos, com ameaças de destruição sempre presentes, como a poluição, os desastres naturais, as guerras, a crescente urbanização a exploração dos recursos naturais, a pobreza e até a massificação do turismo. Por isso, têm-se dedicado cada vez mais à conservação da paisagem e do património que lhe está associado, criando-se para o efeito normas e critérios de avaliação que possam vir a fazer parte do património mundial, contribuindo assim para a sua conservação.

Constata-se que o Buçaco apresenta uma longa linha espácio-temporal que passa por episódios da história nacional, particularmente pelos monges Beneditinos e Carmelitas Descalços e a sua ação arborizadora e técnicas florestais que no intuito de recriarem um ambiente místico e religioso edificaram um vasto património.

A singularidade do Buçaco tem sido confirmada por ser um espaço de refúgio e isolamento religioso, período militar marcante da história, assim como um local de lazer e romantismo. O efeito cénico do luar, cuja luz se projeta e reflete nesta paisagem única cria um ambiente de pura espiritualidade e meditação que constitui um dos melhores e mais emblemáticos refúgios naturais do País.

A paisagem cultural tem sido um espaço dinâmico com ciclos de tempo muito diferentes, apropriado por múltiplos agentes. A paisagem é por isso um instrumento fundamental para que no futuro se possa ver, cheirar, ouvir e sentir o Buçaco numa dimensão multissensorial, dando-lhe assim um valor acrescido. É nesta paisagem que se encontra a convergência do material e do imaterial, princípios e valores patrimoniais com várias influências. A paisagem cultural do Buçaco foi, também resgatada por uma ideologia de matriz nacionalista monárquica que veio trazer profundas alterações não só paisagística mas também arquitetónica, produzida com contornos cenográficos e representativos dos feitos nacionais.

Para concluir salienta-se que uma estreita ligação entre o Buçaco e a paisagem cultural pode permitir um maior desenvolvimento no ensino e aprendizagem do património e uma melhor consolidação de conhecimentos, vínculos e valores consubstanciados numa nova cidadania para o séc. XXI.

\section{Bibliografia}

Augé, Marc (1998) - Os não-lugares. $2^{\mathrm{a}}$ Ed. Bertrand, Lisboa. Cortesão, Jaime (1978) "A elegia mística do Buçaco". In: Nemésıo, Vitorino (Org.) Portugal a Terra e o Homem - antologia de escritores dos séculos XIX-XX. Fundação Calouste Gulbenkian, Lisboa, pp. 133-135.

CoRtes̃̃o, Jaime (1987) - Portugal: a Terra e o Homem. INCM, Lisboa.

Dıonisıo, Santana (1944) - Guia de Portugal. Beira Litoral, Beira Baixa e Beira Alta. Vol. 3. Biblioteca Nacional, Lisboa.

GASPAR, Jorge (2001) - "O retorno da paisagem à geografia apontamentos míticos". Revista Finisterra, Lisboa, vol. XXXVI, No 72 , pp. 83-99.

Luginbuhl, Yves (1992) - Nature paysage et environment, obscure objects du désir de totalité. Paris Económica, pp. 13-56.

Peralta, Elsa e Anico, Marta (2007) - Patrimónios e identidades ficções contemporâneas. Celta Editora, Oeiras.

Pereira, Paulo (2005) - Património edificado: pedras angulares. Edição do Autor, [s.l.].

Pereira, Paulo (2010) - Lugares mágicos de Portugal. Círculo de Leitores, Temas e Debates, Lisboa. 
PorTeus, J. Douglas (1985) - "Smellscape". Progress in Human Geography. vol. 9, n³, pp. 356-378.

RIBEIRo, Orlando (1993) - Geografia de Portugal: posição geográfica e território (Vol. 1). Edições João Sá Costa, Lisboa.

RIMBERT, Sylvie (1973) - "Approches des paysages". L'espace Géographique, vol. 2, n 3 , pp. 233-241.
Salgueiro, Teresa Barata (2001) - "Paisagem e geografia". Revista Finisterra, Vol. XXXVI, $\mathrm{n}^{\circ} 72$, Lisboa, pp. 3753.

SAYYA, Al (2001) - Consuming tradition - manufactoring heritage: global norms and urban forms in the age of tourism. Routledge, Londres. 